\title{
Intra-articulaire calcaneusfracturen
}

Drs T. Schepers AIOS Heelkunde

Prof. Dr. P. Patka Sectorhoofd Traumatologie

Correspondentie adres:

T. Schepers

Erasmus MC, Afdeling Heelkunde-Traumatologie

Kamer H 974

P.O. Box 2040

3000 CA Rotterdam, Nederland

Tel: 010-4631050

Fax: 010-4632396

E-mail: t.schepers@erasmusmc.nl 


\title{
SAMENVATTING
}

Slechts $0.6 \%$ van alle fracturen in Nederland betreft een intra-articulaire calcaneusfractuur. Vaak heeft de patiënt additionele letsels en terugkeer in het arbeidsproces kan een jaar in beslag nemen. De initiële diagnostiek bestaat uit een laterale en axiale röntgenfoto van de calcaneus en wordt vaak aangevuld met een CTscan met reconstructies in drie richtingen. Door het ontbreken van standaardisatie met betrekking tot classificatie en uitkomstmaten van intra-articulaire calcaneusfracturen is de beste behandelmethode nog onduidelijk.

Er zullen in de toekomst meer gerandomiseerde onderzoeken uitgevoerd moeten worden om de juiste techniek voor de behandeling van de verschillende fractuurtypen te bepalen.

\begin{abstract}
About $0.6 \%$ of all fractures is an intra-articular calcaneal fracture. Patients often have additional injuries, and returning to work can take up to one year. The diagnostics consist of plain, lateral and axial, radiographs of the calcaneus. In addition a CT-scan is performed in three planes. Because of the lack of a standardised classification and disease specific outcome-scores there is no agreement on the best treatment modality. More randomised controlled trials are mandatory in the future to determine the best treatment modality for the different types of intra-articular calcaneal fractures.
\end{abstract}

\section{TREFWOORDEN}

Calcaneus, fractuur, diagnostiek, behandeling, resultaten 


\section{INLEIDING}

Intra-articulaire calcaneusfracturen zijn een relatief zeldzaam letsel, waardoor de diagnostiek en de juiste behandeling minder goed bekend zijn. In dit artikel worden de belangrijkste aspecten van de calcaneusfractuur besproken, met als doel een verbreding van het inzicht in deze complexe fractuur, zodat patiënten niet alleen beter voorgelicht kunnen worden, maar tevens een meer uniforme behandeling verkrijgen. 


\section{EPIDEMIOLOGIE}

Met een incidentie in de literatuur van 1-2\% van alle fracturen is de calcaneusfractuur een zeldzaam letsel. ${ }^{1}$ In Nederland wordt deze incidentie geschat op $0.6 \%{ }^{2}$ Ongeveer $75 \%$ van deze fracturen is intra-articulair en heeft een slechtere prognose in vergelijking met extra-articulaire fracturen. ${ }^{3}$ Val van enige hoogte, zoals een val van de trap of tentamen suicidii, vormen meer dan $80 \%$ van de traumamechanismen van de intra-articulaire calcaneusfracturen. Arbeidsongevallen maken ongeveer de helft van deze groep uit. ${ }^{4}$ De overige $20 \%$ zijn fracturen die ontstaan bij verkeersongevallen of direct letsel. De overgrote meerderheid van calcaneusfracturen, $80-90 \%$, komt bij mannen voor, meestal van middelbare leeftijd. ${ }^{1}$ Slechts $5 \%$ van alle calcaneus fracturen komt bij kinderen voor. ${ }^{5}$ Begeleidende fracturen en andere letsels treden bij 20 tot $60 \%$ van de patiënten op. Dit betreft meestal een fractuur van de contra- of ipsilaterale onderste extremiteit; een bilaterale calcaneusfractuur wordt bij ongeveer $10 \%$ van de patiënten gezien. ${ }^{4,6,7}$. Een van de meest voorkomende begeleidende letsels, bij $10 \%$ van de patiënten, is een fractuur van de lumbale wervelkolom. ${ }^{5}$ Een andere bekende combinatie is een fractuur van de calcaneus, gecombineerd met een fractuur van de onderarm en een wervel fractuur. Deze combinatie wordt de 'Lovers triad' genoemd, naar de mannen die van het balkon van hun geliefde sprongen, indien ze betrapt werden.

Door het grote aantal mensen van middelbare leeftijd, bedrijfsongevallen en de lange revalidatieperiode, is aan de calcaneusfractuur ook een groot economische belang verbonden. ${ }^{8}$ De jaarlijkse kosten in Nederland van intra-articulaire calcaneusfracturen worden geraamd op 20.5 tot 30.7 miljoen Euro. ${ }^{2}$ 


\section{TRAUMAMECHANISME}

Het traumamechanisme bij de intra-articulaire calcaneus fractuur is door diverse auteurs beschreven, waarvan de meest bekende Böhler, Palmer, Essex-Lopresti en Warrick en Bremner zijn. ${ }^{8-12}$ Door de axiale krachten die ontstaan bij een rechtstandige val op de voet, werkt de talus als een wig, die de calcaneus splijt ter hoogte van de sinus tarsi. Op de laterale röntgenfoto is dit te zien ter hoogte van de hoek volgens Gissane [Figuur 1a] doorlopend naar de plantaire zijde van de calcaneus. De fractuur die hierdoor ontstaat, werd door Essex-Lopresti de primaire fractuurlijn genoemd. ${ }^{11}$ Door het iets mediaal liggende zwaartepunt van de talus t.o.v. het zwaartepunt van de calcaneus zal de primaire fractuurlijn de calcaneus in twee delen splijten, te weten het posterolaterale tuberositas fragment en het anteromediale sustentaculum fragment. ${ }^{13}$ Dit laatste fragment zit met diverse ligamenten (lig. talocalcaneum interosseum en lig. talocalcaneum mediale van het lig. deltoideum) vast aan de talus en de mediale malleolus en zal in de regel slechts weinig disloceren. Bij het doorwerken van de verticale belasting zal een secundaire fractuurlijn vanaf de hoek van Gissane door het tuberositas calcanei fragment lopen. De richting waarin deze secundaire fractuurlijn zich uitbreidt, vormt de basis van de classificatie van Essex-Lopresti [Figuur $1 \mathrm{~b}-\mathrm{d}$ ]. Bij een nog grotere kracht zullen er naast de primaire en secundaire fractuurlijnen zich meerdere fractuurlijnen vormen en dus meerdere fragmenten ontstaan. ${ }^{13}$ 


\section{KLINIEK}

Veelal komen de patiënten met een calcaneus fractuur in het ziekenhuis op de Spoedeisende Hulp of, minder frequent, bij de huisarts terecht, omdat zij vanwege pijn van de hiel het been niet meer kunnen belasten.

Bij het lichamelijk onderzoek staat de pijn van de hiel en de drukpijn rondom de calcaneus op de voorgrond, vaak begeleid door zwelling en hematomen. Karakterestiek is dat het hematoom bij calcaneusfracturen kan uitbreiden naar de voetzool, het zgn 'teken van Mondor', terwijl dit bij enkelfracturen zelden gezien wordt. ${ }^{10,14}$ Door de zwelling treedt vaak blaarvorming van de voet op. De aangedane voet is vanwege de pijn niet belastbaar. ${ }^{10}$ In ongeveer $10 \%$ van de calcaneusfracturen is sprake van een gecompliceerde fractuur. ${ }^{15}$ Toenemende pijnklachten kunnen wijzen op een acuut compartiment syndroom. ${ }^{16}$ Ook aan begeleidende letsels, zoals de wervelkolom letsels, moet aandacht besteed worden. 


\section{RADIOLOGIE EN CLASSIFICATIE}

Bij een verdenking op een calcaneusfractuur bestaat het initiële radiologisch onderzoek uit een zijwaartse en een axiale opname van de voet; meestal is hiermee de diagnose calcaneusfractuur al te stellen. Behulpzaam hierbij is het bepalen van twee hoeken op de laterale röntgenfoto [Figuur 1a]. De zogenaamde 'tuber-joint angle' volgens Böhler wordt bepaald door de lijn lopend van de punt van de anterior processus calcanei naar het hoogste punt van het posterior facet en de lijn vanaf de bovenzijde van de tuberositas calcanei naar het hoogste punt van het gewricht. Normaal is deze hoek tussen de 25 en de 40 graden. ${ }^{10}$ De tweede hoek die gemeten kan worden is de 'crucial-angle' volgens Gissane. Deze loopt langs de posterior zijde van de anterior processus en de voorzijde van het subtalaire gewricht. Normaal ligt deze hoek tussen de 120 en de 145 graden. ${ }^{11}$ Deze twee hoeken geven de mate van depressie en verplaatsing van het subtalaire gewricht weer. Uit onderzoek is gebleken dat deze zijwaartse en axiale foto's het belangrijkse gewricht, het posterieure facet, slechts ten dele afbeelden. ${ }^{17}$ Om deze reden zijn er in de loop der jaren diverse aanvullende röntgenopnamen (volgens Brodén, Isherwood, Anthonson en HarrisBeath) ontwikkeld om het subtalaire gewricht volledig in kaart te brengen. ${ }^{9,}{ }^{18}$ Met de komst van de CT-scan begin jaren tachtig werden de bovengenoemde aanvullende opnames overbodig. Meestal wordt direct na het vervaardigen van de laterale en de axiale foto's een CT-scan gemaakt. Hierbij worden in de verschillende richtingen, coronair, sagittaal en transversaal, reconstructies gemaakt [Figuur 2]. Deze tonen met grote nauwkeurigheid de uitgebreidheid van de fractuur, het aantal fragmenten, de mate van verplaatsing van de verschillende fragmenten, verbreding en de conditie van het subtalaire gewricht. ${ }^{9,18}$ 
De classificaties welke ontwikkeld zijn voor calcaneusfracturen zijn te verdelen in de classificaties gebaseerd op conventionele radiografie en de classificaties die voor de CT-scans ontwikkeld zijn. Voor beiden geldt dat het onderscheid tussen intra- en extra-articulaire fracturen het meest belangrijk is. Dit artikel beperkt zich tot de eerste groep.

Een van de eerste classificaties, gebaseerd op conventionele röntgenfoto's, is die van Böhler in 1931. Sindsdien zijn er meer dan twintig verschillende classificaties beschreven. ${ }^{8}$ De meest gebruikte is die van Essex-Lopresti uit 1952, mede omdat het een relatief eenvoudige classificatie is en omdat deze correleert met de operatietechniek en de resultaten van de behandeling. Essex-Lopresti onderscheidde twee typen intra-articulaire fracturen, bepaald door de richting van de secundaire fractuurlijn, te weten de 'Joint-depresssion' en het 'Tongue' type [Figuur 1b-d]. Bij meer dan twee fractuurlijnen spreekt men van een comminutieve fractuur. ${ }^{11}$

De CT-scan verschaft meer informatie over de conditie van het subtalaire gewricht. In de loop der jaren zijn er ruim tien classificaties verschenen die gebaseerd zijn op CT-scans van intra-articulaire calcaneus fracturen. Allen beschrijven de mate van destructie van het posterieure facet. De meest toegepaste classificatie is die van Sanders. Op de (semi-)coronale coupes, waarbij het posterior facet op zijn breedst is en het sustentaculum tali zichtbaar is, wordt het aantal fractuurlijnen met verplaatsing (meer dan $2 \mathrm{~mm}$ ) geteld. Eén fractuurlijn door het achterste spronggewricht is een Sanders type II fractuur, twee fractuurlijnen een type III en drie of meer verplaatste fractuurlijnen een type IV. Indien de fractuurdelen onverplaatst zijn betreft het een type I fractuur. De fractuurlijnen zijn van lateraal naar mediaal genummerd (ABC). Afhankelijk van de locatie van de fractuurlijn zijn er drie vormen typen II en III. ${ }^{8}$ [Figuur 2 en 3]. Uit meerdere studies is gebleken dat de classificatie van Sanders 
relatief eenvoudig is, met redelijke intra-onderzoeker variabiliteit. ${ }^{19}$ Daarnaast is er enige mate van voorspellende waarde ten aanzien van de prognose, waarbij de patiënten met een type II fractuur het beter doen dan patiënten met een type III, welke een beter resultaat hebben ten opzichte van de patiënten met een type IV fracturen. ${ }^{20}$ 


\section{THERAPIE}

De behandeling van intra-articulaire calcaneusfracturen is onder te verdelen in twee groepen: conservatief en operatief.

De conservatieve behandeling bestaat uit rust, elevatie, kortdurend gips tot de ergste pijn en zwelling zijn afgenomen en vroeg starten met oefenen. Het vroeg en actief oefenen van de voet lijkt daarbij superieure resultaten te geven in vergelijking met lange gipsimmobilisatie. ${ }^{11,21}$ De gemiddelde duur van onbelast mobiliseren is 8 tot 12 weken. ${ }^{8}$ Fracturen die in aanmerking komen voor een conservatieve behandeling zijn onverplaatste fracturen, patiënten bij wie een slechte compliantie verwacht wordt ten aanzien van wondcontroles en onbelast mobiliseren, een slechte conditie van de weke delen (bv. open fracturen, blaarvorming) en wanneer een operatieve behandeling gecontra-indiceerd is. In Nederland wordt ongeveer $40 \%$ van de intra-articulaire calcaneusfracturen conservatief behandeld. ${ }^{2}$

Het doel van operatieve behandeling is op de eerste plaats het herstellen van de congruïteit van het subtalaire gewricht, ten tweede het herstellen van de hoogte en het reduceren van de verbreding van de calcaneus. Men beoogt hiermee het pijnvrij kunnen lopen, de terugkeer naar het werk en het kunnen dragen van normaal schoeisel te bereiken. Er zijn vele operatieve technieken voor calcaneusfracturen beschreven. Deze zijn onder te verdelen in: 'gesloten', 'percutaan' en 'open' repositie en fixatie technieken. De gesloten operatieve techniek bestaat uit het niet-invasief manipuleren van de fractuur om een betere stand te verkrijgen. ${ }^{22}$ Een van de eerste percutane technieken werd door Westhues bedacht en door Essex-Lopresti verder ontwikkeld, in het bijzonder voor de 'tongue-type' fracturen. Deze methode bestaat uit het inbrengen van een metalen pin, de 'Gissane-spike', via de posterior zijde van de hiel in de tuberositas van de calcaneus om zo de fragmenten te reponeren. ${ }^{11}$ Een andere vaak 
toegepaste percutane techniek is de drie-punts distractie volgens Forgon en Zadravecz. ${ }^{7,23-25}$

De 'open' operatieve techniek wordt ingedeeld naar de benaderingszijde: laterale benadering, mediaal en gecombineerd zijn daarbij de meest gangbare. Het meest frequent gebruikt, en gepropageerd door de Arbeitsgemeinschaft für Osteosynthesefragen, is de 'extended lateral approach'. ${ }^{26}$ Door een L-vormige incisie kan een goed beeld verkregen worden van het gewricht om het zodoende te herstellen. Enkele chirurgen zijn van mening dat herstel van het subtalaire gewricht bij een comminutieve fractuur niet mogelijk is en dat het opheffen van het subtalaire gewricht, een primaire arthrodese, de beste optie is. ${ }^{8}$

Belangrijk in de behandeling is de tijdsplanning van de operatie. De gesloten en percutane technieken dienen binnen enkele dagen te geschieden, opdat de fractuurdelen nog maximaal beweeglijk zijn en door distractie te reponeren zijn. ${ }^{7,22}$ De open techniek heeft vanwege wondgenezingsstoornissen een slechte reputatie. Wondgenezing verloopt beter als de weke-delen voldoende tijd gekregen hebben te ontzwellen. ${ }^{8}$ De mate van ontzwellen is fraai te illustreren met de 'wrinckle-test' volgens Sanders. Na maximale plantair flexie geeft de huid, van een voldoende afgeslankte voet, rimpels wanneer deze weer in neutrale stand gehouden wordt. ${ }^{8}$ Daarnaast lijkt roken een significant verhoogde kans op wondcomplicaties te geven. ${ }^{27}$ Er bestaan geen absolute contra-indicaties voor de operatieve behandeling van verplaatste intra-articulaire calcaneusfracturen, wel zijn er enkele relatieve contraindicaties voor met name de open benadering. Ernstige co-morbiditeit welke opereren niet mogelijk maakt, zowel pre-existent als trauma-gerelateerd is een contra-indicatie. Daarnaast zijn perifeer vaatlijden en insuline-afhankelijke diabetes, gezien de verhoogde kans op wondcomplicaties, en ongevals-gerelateerde weke-delen 
problemen, zoals open-fracturen en uitgebreide blaarvorming zijn de belangrijkste contra-indicaties voor een open-operatieve behandeling. In deze gevallen kan een conservatieve behandeling of soms een percutane repositie en fixatie overwogen worden. 


\section{RESULTATEN}

Om de resultaten van diverse behandeltechieken te bepalen zijn in de afgelopen eeuw enkele honderden artikelen verschenen. De belangrijkste meetpunten van de behandeling zijn: pijnklachten, beperkingen in het dagelijks leven, kwaliteit van lopen, dragen van normaal schoeisel, terugkeer in het arbeidsproces en de beweeglijkheid van de enkel.

Om het eindresultaat te meten zijn er meer dan dertig ziektespecifieke uitkomstscores ontwikkeld. De meest gebruikte in de literatuur is die van de American Orthopaedic Foot and Ankle Society, de AOFAS-hindfoot score, welke uit negen items betreffende pijnklachten, beperkingen, looppatroon, loopafstand, loopoppervlak en lichamelijk onderzoek (beweeglijkheid bovenste en onderste spronggewricht, stabiliteit en voet-positie) bestaat. In totaal kan een score van maximaal 100 punten verkregen worden. ${ }^{28}$ Meer dan 75 punten wordt beschouwd als een goed tot uitstekend resultaat. ${ }^{29}$ Slechtere resultaten zijn te verwachten bij zeer comminutieve fracturen en bij gecompliceerde, open, fracturen. De vragenlijst dient aangevuld te worden met een lichamelijk onderzoek, waarbij de beweeglijkheid van het enkel- en van het subtalaire gewricht bepaald wordt, gebruik makende van een goniometer. Bij een bilaterale fractuur kunnen normaal waarden gebruikt worden ter vergelijk. De beweeglijkheid (ROM: range of motion) van het enkelgewricht in het sagittale vlak is 40-55 graden flexie, en 20-30 graden extensie. ${ }^{30}$ Het subtalaire gewricht heeft een beweeglijkheid van 5 graden eversie en 20-25 graden inversie. ${ }^{30}$ De correlatie tussen resultaat van de behandeling en controle röntgenfoto's staat nog ter discussie. ${ }^{18}$

In de literatuur wordt in 25 tot $75 \%$ van de patiënten een goed tot uitstekend resultaat bereikt na conservatieve behandeling. Gemiddeld heeft de helft van de 
patiënten die conservatief behandeld is een acceptabel resultaat. ${ }^{13,31}$ Patiënten met een gesloten repositie scoren iets beter: in 45 tot $90 \%$ van de patiënten wordt een goed tot uitstekend resultaat bereikt. ${ }^{22,}{ }^{32}$ De patiënten na een percutane repositie en fixatie scoren tussen de 60 en de $80 \%$ goed tot uitstekend resultaat. ${ }^{7,11,23}$ Open repositie en interne fixatie scoort het meest gunstig in retrospectieve series. Patiënten scoren hierbij tussen de 70 en de $90 \%$ goed tot uitstekend resultaat. $8,12,33,34$

De resultaten van de primaire arthrodese liggen tussen de 50 en de $74 \%$ tevreden resultaat, gemeten met een ziektespecifieke uitkomstscore door de patiënten. $^{35}$

De recente meta-analyse van Bajammal uit 2005 bundelde de resultaten van 4 gerandomiseerde studies, waarbij gerandomiseerd werd tussen een conservatief beleid en de open repositie en interne fixatie (O’Farrell, Parmar, Thordarson en Buckley) ${ }^{4,36-}$ ${ }^{38} .{ }^{39}$ Conclusies uit deze meta-analyse waren (Bewijskracht B):

- Er is geen significant verschil in pijn en functionele uitkomst tussen operatief en conservatief behandelde patiënten.

- Met betrekking tot terugkeer naar het arbeidsproces en de mogelijkheid om normale, niet aangepaste, schoenen te dragen lijken operatief behandelde patiënten beter te scoren dan conservatief behandelde patiënten.

- Er is een significante reductie in de kans op een late arthrodese na operatief behandelde calcaneusfracturen.

- Vanuit een sociaal perspectief is de operatieve behandeling minder duur en meer kosteneffectief dan conservatieve behandeling.

- Het complicatiepercentage in de operatieve groep is hoger dan in de conservatieve groep, met name t.g.v. de infectieuze complicaties. 
In totaal keert $40-85 \%$ van de patiënten, die voor het ontstaan van een calcaneus fractuur een baan hadden, binnen 9 maanden weer naar hun werk terug, al dan niet in een aangepaste vorm. ${ }^{1}$ Ongeveer $20 \%$ is echter na een jaar nog niet teruggekeerd in het arbeidsproces. ${ }^{31}$ 


\section{COMPLICATIES}

Gemiddeld 2-10\% van de calcaneus fracturen wordt gecompliceerd door een compartimentsyndroom van de voet. ${ }^{1,2,4,8,40}$ Het voetcompartimentsyndroom, na een calcaneusfractuur, kenmerkt zich door forse zwelling, buiten-proportionele pijn, paresthesieën of een doof gevoel van de voetzool (nervus plantaris) en dient zo spoedig mogelijk middels een fasciotomie behandeld te worden. ${ }^{40}$ Onbehandeld kan een voetcompartimentsyndroom tot klauwtenen leiden. ${ }^{40}$ Oppervlakkige infectie, osteomyelitis en andere wondcomplicaties vormen de grootste groep acute postoperatieve complicaties. Oppervlakkige infecties komen in $10-27 \%$ van de gevallen voor en osteomyelitis tot ongeveer $2.5 \% .^{8,41}$ Open fracturen vormen een aparte groep, met een vergrootte kans op complicaties en slechtere prognose. ${ }^{15}$ Een nauwe samenwerking met de plastisch chirurg kan hier wenselijk zijn om een adequate bedekking van de open fractuur of weke-delen defect na een geopereerde fractuur te verkrijgen. ${ }^{15,42}$

Arthrose ontstaat in bijna driekwart van de patënten en is daarmee de meest frequent voorkomende complicatie op lange termijn. Niet elke arthrose van het subtalaire gewricht resulteert in de noodzaak tot een arthrodese. De 'arthrodesekansen' van conservatief en operatief behandelde fracturen liggen respectievelijk tussen de 20 en $40 \%$ en tussen de 5 en $15 \%$. $^{3,7,20,32,41}$ Het is onduidelijk welk type arthrodese, in-situ, distractie of triple arthrodese, de beste verbetering van klachten biedt. $^{43}$ 


\section{BESCHOUWING}

De intra-articulaire calcaneusfractuur is een zeldzame botbreuk, waarvoor na jaren onderzoek nog steeds geen eenduidig beleid voor behandeling bestaat. Er lijkt een trend te bestaan in het voordeel van operatieve behandeling, waarvan een vroegere terugkeer naar het werk het resultaat zou zijn. Hier tegenover staat het duidelijk verhoogde complicatie-risico na de operatieve ingrepen. Een kanttekening die hierbij gemaakt moet worden is dat de beste resultaten in grote volume centra behaald worden, aangezien er een duidelijke leercurve voor de operatieve behandeling bestaat van ongeveer 35 tot 50 fracturen. ${ }^{20}$ Volgens de in Nederland gehouden enquête, zal deze leercurve ongeveer vier jaar duren, aangezien slechts 3 van de responderende centra meer dan 20 fracturen op jaarbasis behandelen. ${ }^{2,20}$

Er zullen 'gouden standaarden' met betrekking tot de classificaties en uitkomstscores gedefinieerd moeten worden, opdat verschillende studies beter vergelijkbaar worden en data 'gepooled' kunnen worden in een meta-analyse. Tevens zullen er meer gerandomiseerde, prospectieve studies moeten plaats vinden om de verschillende behandelmethoden te vergelijken, om zo de beste opties bij de verschillende fractuurtypen vast te stellen. In Nederland is recent een dergelijke studie, de Closed Reduction vs ORIF vs Non-Operative Study (CRONOS), gestart. Informatie hierover is te vinden op www.calcaneus.nl. 


\section{REFERENTIES}

1. Barei DP, Bellabarba C, Sangeorzan BJ, e.a. Fractures of the calcaneus. Orthop Clin North Am. 2002;33:263-85.

2. Schepers T, van Lieshout EM, van Ginhoven TM, e.a. Current concepts in the treatment of intra-articular calcaneal fractures: results of a nationwide survey. Int Orthop. 2007 Jun 13.

3. Csizy M, Buckley R, Tough S, e.a. Displaced intra-articular calcaneal fractures: variables predicting late subtalar fusion. J Orthop Trauma. 2003 Feb;17:106-12.

4. Buckley R, Tough S, McCormack R, e.a. Operative compared with nonoperative treatment of displaced intra-articular calcaneal fractures: a prospective, randomized, controlled multicenter trial. J Bone Joint Surg Am. 2002 Oct;84-A:1733-44.

5. Schmidt TL, Weiner DS. Calcaneal fractures in children. An evaluation of the nature of the injury in 56 children. Clin Orthop. 1982 Nov-Dec:150-5.

6. Atkins RM, Allen PE, Livingstone JA. Demographic features of intra-articular fractures of the calcaneum. Foot and Ankle Surgery. 2001;7:77-84.

7. Schepers T, Schipper IB, Vogels LM, e.a. Percutaneous treatment of displaced intraarticular calcaneal fractures. J Orthop Sci. 2007 Jan;12:22-7.

8. Sanders R. Displaced intra-articular fractures of the calcaneus. J Bone Joint Surg Am. $2000 \mathrm{Feb} ; 82: 225-50$.

9. Giachino AA, Uhthoff HK. Intra-articular fractures of the calcaneus. J Bone Joint Surg Am. 1989 Jun;71:784-7.

10. Böhler L. Diagnosis, pathology and treatment of fractures of the os calcis. J Bone Joint Surg. 1931;13:75-89.

11. Essex-Lopresti P. Mechanism, reduction technique and results in fractures of os calcis. Br J Surg. 1952;39:395-419.

12. Palmer I. The mechanism and treatment of fractures of the calcaneus. J Bone Joint Surg. 1948;30-A:2-8.

13. Hammesfahr R, Fleming LL. Calcaneal fractures: a good prognosis. Foot Ankle. 1981 Nov;2:161-71.

14. Richman JD, Barre PS. The plantar ecchymosis sign in fractures of the calcaneus. Clin Orthop Relat Res. 1986 Jun:122-5.

15. Heier KA, Infante AF, Walling AK, e.a. Open fractures of the calcaneus: soft-tissue injury determines outcome. J Bone Joint Surg Am. 2003 Dec;85-A:2276-82.

16. Hans KM, Wille J, Vries JPPMd. Het acute compartimentsyndroom van de voet. Ned Tijdschr Geneeskd. 2004;148:2231-4.

17. Shereff MJ, Johnson KA. Radiographic anatomy of the hindfoot. Clin Orthop. 1983 Jul-Aug:16-22.

18. Schepers T, Ginai AZ, Mulder PG, e.a. Radiographic evaluation of calcaneal fractures: to measure or not to measure. Skeletal Radiol. 2007 Jun 7.

19. Bhattacharya R, Vassan UT, Finn P, e.a. Sanders classification of fractures of the os calcis. J Bone Joint Surg. 2005;87-B:205-8.

20. Sanders R, Fortin P, DiPasquale T, e.a. Operative treatment in 120 displaced intraarticular calcaneal fractures. Results using a prognostic computed tomography scan classification. Clin Orthop. 1993 May:87-95.

21. Carothers RG, Lyons JF. Early mobilization in treatment of os calcis fractures. Am J Surg. 1952;83:279-80.

22. Omoto H, Sakurada K, Sugi M, e.a. A new method of manual reduction for intraarticular fracture of the calcaneus. Clin Orthop. 1983 Jul-Aug:104-11.

23. Rammelt S, Amlang M, Barthel S, e.a. Minimally-invasive treatment of calcaneal fractures. Injury. 2004 Sep;35 Suppl 2:SB55-63.

24. Boll APM, Biert J, Schoots FJ. Onbloedige repositie en percutane schroeffixatie van calcaneusfracturen. Ned Tijdschr Traumatologie. 1994;2:87-91. 
25. Forgon M, Zadravecz G. Die Kalkaneusfraktur. Springer-Verlag. Berlin; 1990. p. 1104.

26. AO-Publishing. Intraarticular calcaneal fractures; operative management. Orthop trauma dir. 2004;2:9-16.

27. Assous M, Bhamra MS. Should Os calcis fractures in smokers be fixed? A review of 40 patients. Injury. 2001 Oct;32:631-2.

28. Kitaoka HB, Alexander IJ, Adelaar RS, e.a. Clinical rating systems for the anklehindfoot, midfoot, hallux, and lesser toes. Foot Ankle Int. 1994 Jul;15:349-53.

29. Follak N, Merk M. The benefit of gait analysis in functional diagnostics in the rehabilitation in patients after operative treatment of calcaneal fractures. Foot Ankle Surg. 2003;9:209-14.

30. Ryf C, Weymann A. The neutral zero method. Injury. 1995;26:1-11.

31. Pozo JL, Kirwan EO, Jackson AM. The long-term results of conservative management of severely displaced fractures of the calcaneus. J Bone Joint Surg Br. 1984 May;66:386-90.

32. Crosby LA, Fitzgibbons T. Intraarticular calcaneal fractures. Results of closed treatment. Clin Orthop. 1993 May:47-54.

33. Zwipp H, Tscherne H, Thermann H, e.a. Osteosynthesis of displaced intraarticular fractures of the calcaneus. Results in 123 cases. Clin Orthop. 1993 May:76-86.

34. Letournel E. Open treatment of acute calcaneal fractures. Clin Orthop. 1993 May:607.

35. Lowery RB, Calhoun JH. Fractures of the calcaneus. Part I: Anatomy, injury mechanism, and classification. Foot Ankle Int. 1996 Apr;17:230-5.

36. O'Farrell D, O'Byrne J, McCabe J, e.a. Fractures of the os calcis: improved results with internal fixation. Injury. 1993;24:263-5.

37. Parmar HV, Triffitt PD, Gregg PJ. Intra-articular fractures of the calcaneum treated operatively or conservatively. A prospective study. J Bone Joint Surg Br. 1993 Nov;75:932-7.

38. Thordarson DB, Krieger LE. Operative vs. nonoperative treatment of intra-articular fractures of the calcaneus: a prospective randomized trial. Foot Ankle Int. 1996 Jan;17:2-9.

39. Bajammal S, Tornetta P, 3rd, Sanders D, e.a. Displaced intra-articular calcaneal fractures. J Orthop Trauma. 2005 May-Jun;19:360-4.

40. Andermahr J, Helling HJ, Tsironis K, e.a. Compartment syndrome of the foot. Clin Anat. 2001 May;14:184-9.

41. Zwipp H, Rammelt S, Barthel S. Calcaneal fractures--open reduction and internal fixation (ORIF). Injury. 2004 Sep;35 Suppl 2:SB46-54.

42. Cavadas PC, Landin L. Management of soft-tissue complications of the lateral approach for calcaneal fractures. Plast Reconstr Surg. 2007 Aug;120:459-66; discussion 67-9.

43. Easley ME, Trnka HJ, Schon LC, e.a. Isolated subtalar arthrodesis. J Bone Joint Surg Am. 2000 May;82:613-24. 


\section{FIGUREN}

Figuur 1: Conventionele röntgenfoto's: a. normale calcaneus, met de hoeken volgens Böhler (witte lijn; referentiewaarden 25-40 graden) en Gissane (zwarte lijn; referentiewaarden 120-145 graden), b. joint-depression fractuur volgens Essex-Lopresti, c. 'tongue-type' fractuur, d. comminutieve calcaneusfractuur.
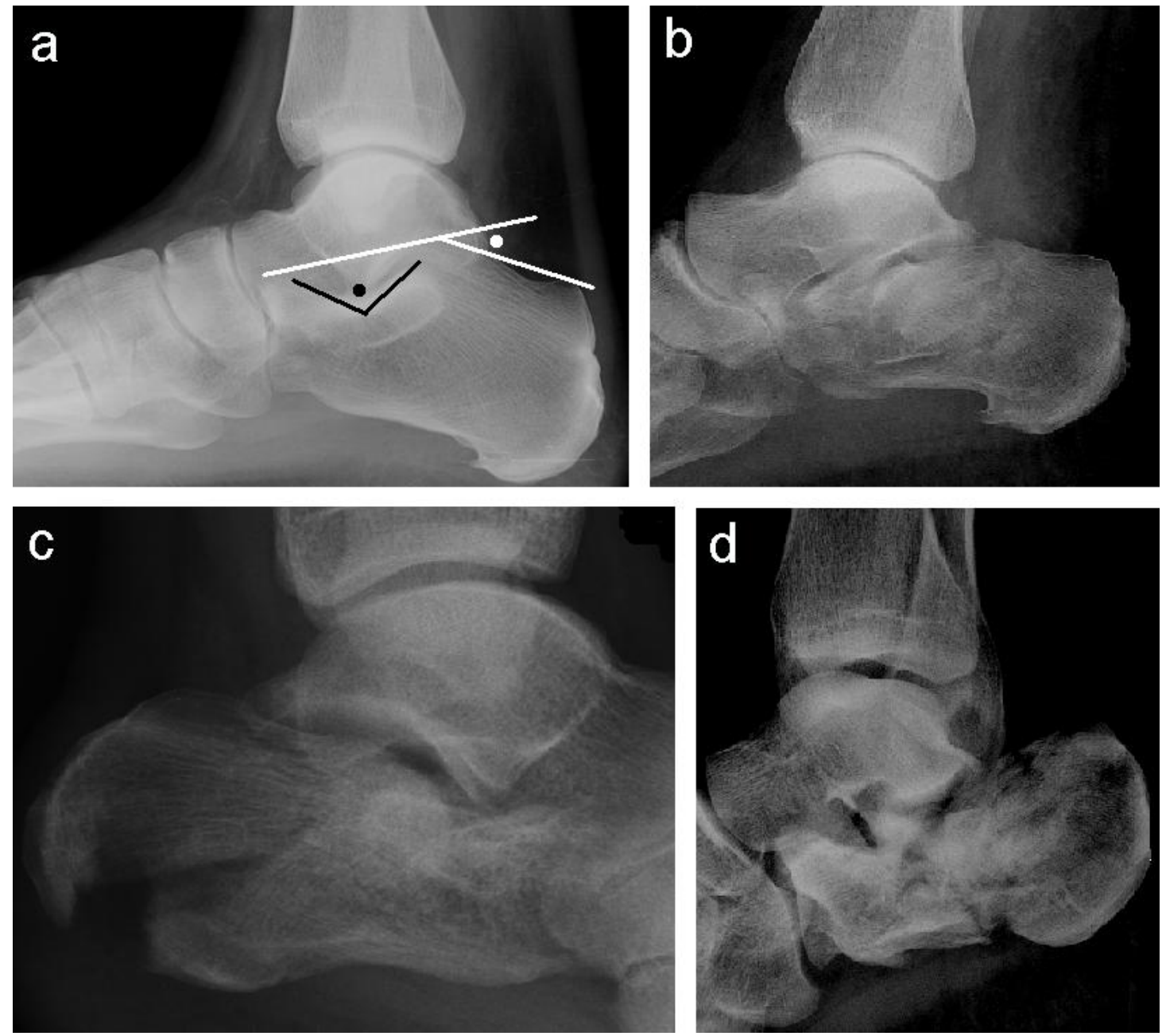
Figuur 2: $\quad$ Voorbeeld van een CT-scan van een calcaneusfractuur, met computer reconstructies in het axiale, semicoronale en sagittale vlak. De fractuur in dit voorbeeld betreft een Sanders IIB type.
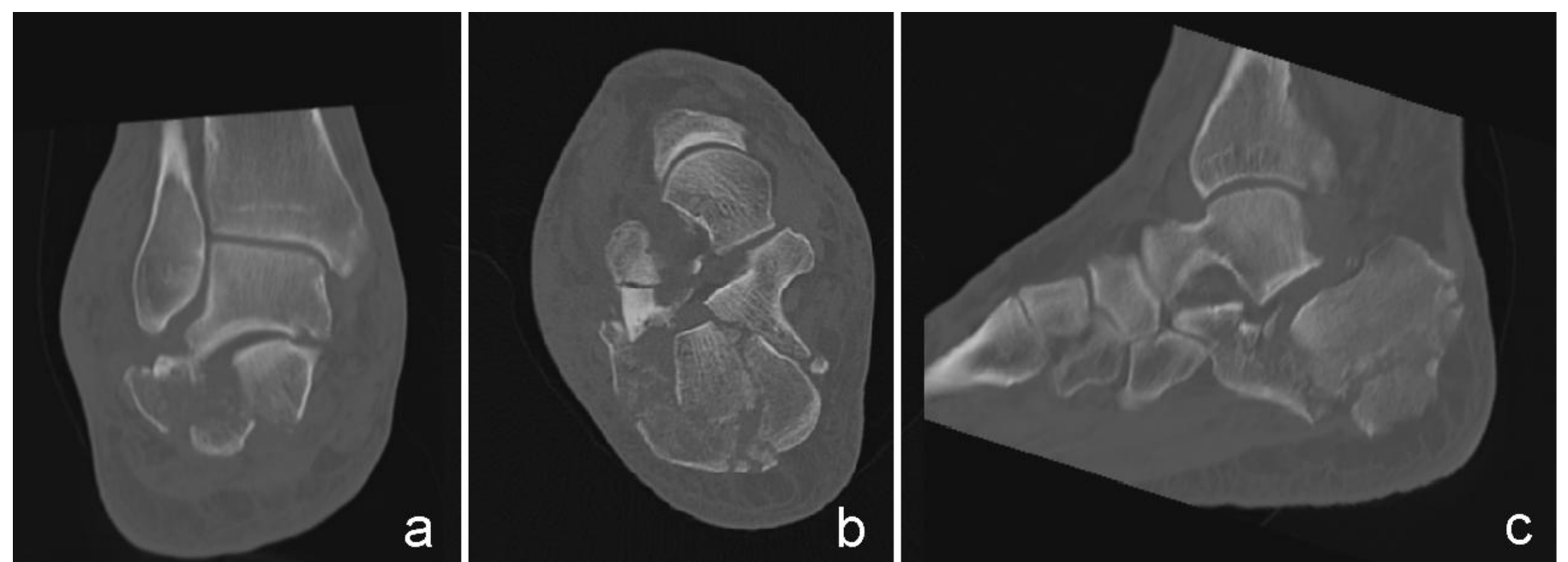
Figuur 3: CT-classificatie volgens Sanders: a. type IIA, b. type IIIAC, en c. type IV fractuur.
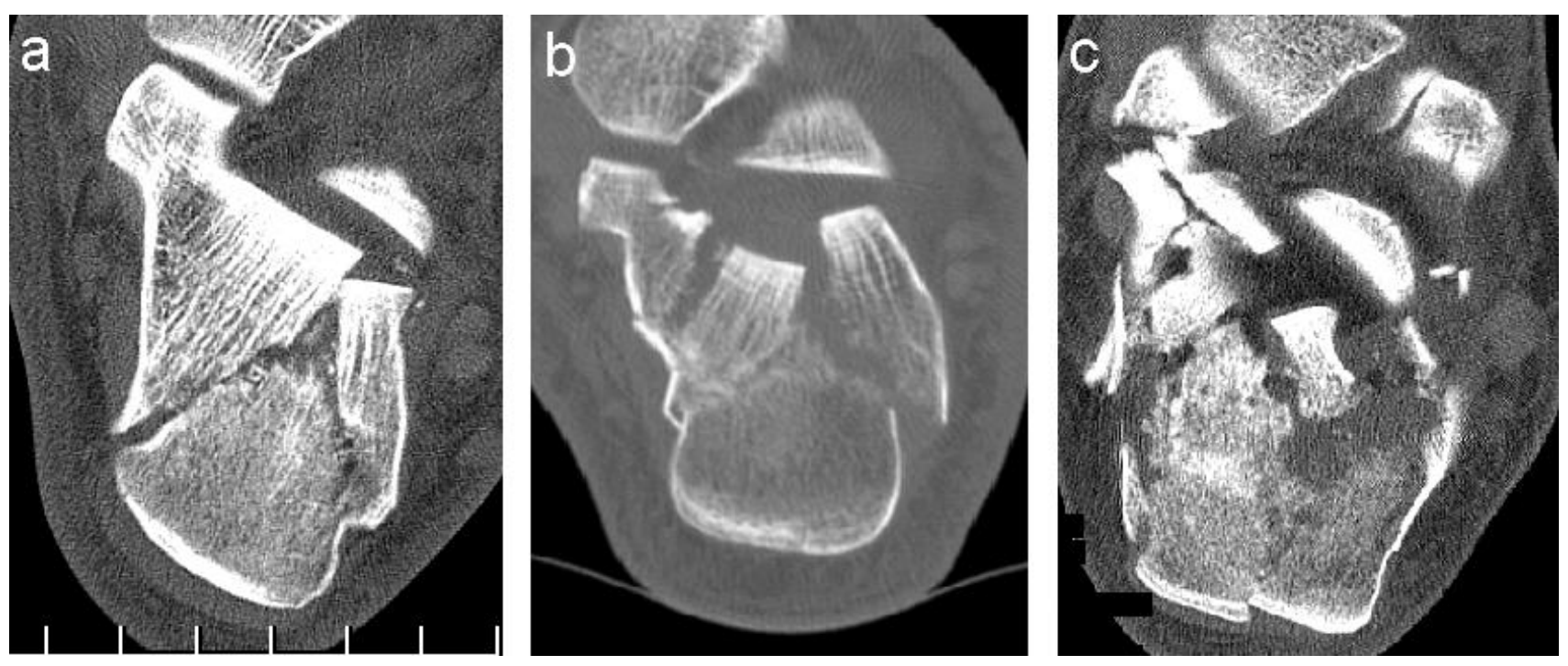